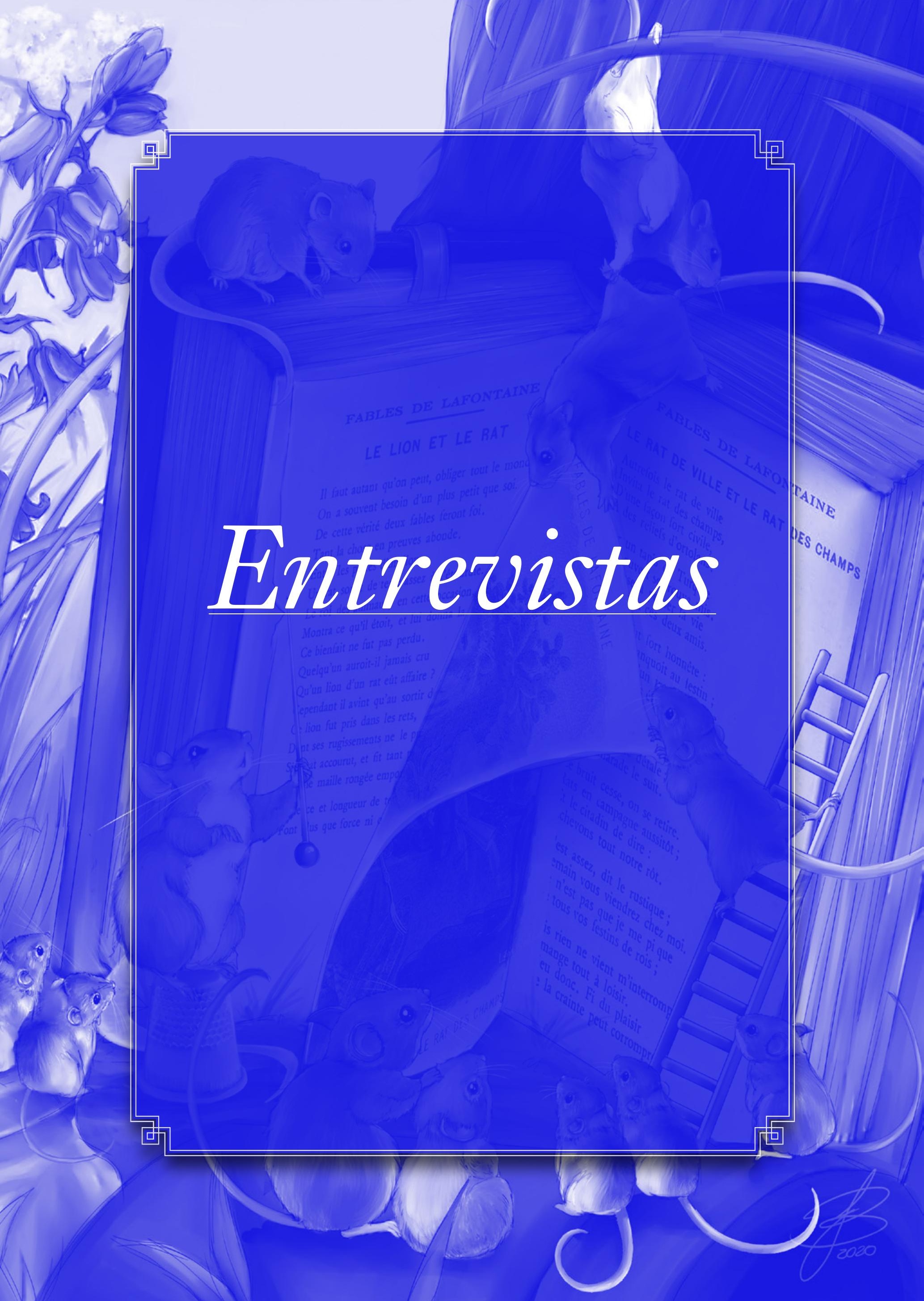




\title{
Uma vida dedicada ao estudo de excelência do conto de fadas, do livro ilustrado e da literatura infantil
}

\author{
Entrevista com a Profa. Dra. Bettina
}

Kümmerling-Meibauer, da Universidade de Tübingen

\author{
A Life dedicated to the excellence research of fairy \\ tales, picturebooks and childrens' literature \\ Interview with professor Bettina Kümmerling-Meibauer, \\ from University of Tübingen
}

\section{André Luiz Ming Garcia}

1 Doutor em Letras (Língua e Literatura Alemã) pela Universidade de São Paulo, onde atualmente realiza pós-doutoramento e atua como professor colaborador. Agradecimentos a Lígia Menna e Cristina Casagrande pelas perguntas sugeridas para esta entrevista. andreming@usp.br. 
Bettina Kümmerling-Meibauer destaca-se, na atualidade, como uma das mais importantes pesquisadoras das temáticas elencadas no título do presente texto, possuindo uma visão ampla e muita experiência acerca desses campos de pesquisa. $\mathrm{Na}$ presente entrevista, debate conosco temas atuais e até polêmicos envolvidos no âmbito do conto de fadas, oferecendo-nos uma visão privilegiada dessas questões decorrente de sua notória expertise. Em sua obra Die Kunstmärchen von Hofmannsthal, Musil und Döblin (Böhlau, 1991), inter-relaciona o conto de fadas popular, o conto de fadas literário e o conto de fadas artístico, além de questionar as origens românticas do conto de fadas literário alemão, o estatuto de conto de fadas de determinadas narrativas contidas na coletânea dos Irmãos Grimm e, assim, abordar com aguda criticidade e com tom inovador questões por muitos consideradas encerradas ou envolvidas pelo consenso, demonstrando a necessidade do dissenso lógico no movimento de expansão do estado da arte de um tema de investigação acadêmica.

O texto que ora se oferece para apreciação põe-nos em privilegiado diálogo com aspectos da pesquisa internacional acerca do conto de fadas. Kümmerling-Meibauer mostra-nos como os estudos acerca desse gênero literário são abordados de formas e a partir de perspectivas distintas na Europa onde, geralmente, o gênero é dissociado dos estudos de Literatura Infantil, por razões a respeito das quais a entrevista nos leva a refletir.

Para além disso, como autora de Kinderliteratur, Kanonbildung und literarische Wertung ["Literatura infantil, formação de cânone e valoração literária”] (Metzler, 2003), também tem muito a nos dizer a respeito do caráter infantil ou não dos contos de fadas e outras textualidades artísticas.

A seguir, encontra-se a entrevista que gentilmente nos cedeu e, ao final, um resumo de seu currículo acadêmico e de suas principais publicações. Boa leitura! 
Em primeiro lugar, informações gerais: a pesquisa de contos de fadas e a literatura infantil são duas disciplinas separadas (inclusive com cadeiras próprias e distintas na estrutura universitária), que se sobrepõem apenas em algumas áreas. Embora tenha feito meu doutorado em contos de fadas, lidei com a pesquisa de contos por anos e também ofereço cursos sobre contos de fadas, mas meu foco está claramente na pesquisa de literatura infantil e não nos estudos sociais. Portanto, as respostas abaixo sempre devem ser vistas sob a perspectiva da pesquisa em literatura infantil a despeito dessa tendência europeia. Consequentemente, não poderei responder a algumas perguntas com tantos detalhes quanto um pesquisador de contos de fadas de fora da literatura infantil certamente faria.

\section{Como a Sra. vê o estado da pesquisa sobre contos de fadas na Euro- pa neste momento? Quais tópicos e aspectos estão sendo pesquisados atualmente com mais frequência?}

A pesquisa de contos de fadas é - pelo menos na Alemanha - frequentemente atribuída aos assuntos de antropologia cultural, folclore, às vezes também pedagogia. Quase não existem, aqui, pesquisadores de contos de fadas nos estudos literários. Os caminhos entre pesquisadores de contos de fadas e pesquisadores de literatura infantil geralmente não se cruzam. Mesmo que haja conferências de contos de fadas para crianças, há mais estudiosos, educadores e educadores literários. Isso é certamente lamentável, mas tem a ver com diferentes interesses. A pesquisa europeia sobre contos de fadas existe a "European Fairy Tale Society e.V.", com sede em Rheine e a "Fairy Tale Foundation Walter Kahn", com sede em Volkach — se baseia mais nos chamados contos populares, incluindo os contos de Grimm, mas mostra menos interesse em pesquisa de contos de fadas artísticos - que, por sua vez, são objeto de pesquisas em estudos literários. Embora a Sociedade Européia 
de Conto de Fadas apoie o intercâmbio acadêmico, é claro pelos estatutos que o interesse é muito mais focado em promover a narrativa e transmitir os contos de fadas como uma herança cultural. Pelo menos na pesquisa alemã de contos de fadas, o foco continua nos contos de Grimm.

\section{Sua tese de doutorado foi sobre contos de fadas artísticos. Mas hoje a Sra. desenvolveu muita experiência em livros ilustrados. Como foi esse processo?}

Isso mesmo. Minha tese examinou os contos de Hugo von Hofmannsthal, Robert Musil e Alfred Döblin, bem como a influência do conto de fadas em suas obras completas. Eu estava particularmente interessada no significado do conto de fadas a partir de sua visão de mundo, porque todos os três autores tinham um interesse eminentemente científico. Como a orientação científica, que também se reflete em suas obras literárias, pode ser conciliada com o conto de fadas? Embora esses três autores não tenham escrito contos de fadas para crianças, indiretamente, é traçada uma linha no meu estudo subsequente da literatura infantil, simplesmente porque o conto é equiparado por muitas pessoas à literatura infantil (mais sobre isso abaixo). Após minha dissertação, reorientei-me e primeiro escrevi um dicionário de dois volumes, "Clássicos da literatura infantil e juvenil”, publicado em 1999 pela Metzler-Verlag. Este dicionário apresenta cerca de 530 clássicos infantis de 65 países (incluindo o Brasil). Minha tese de livre-docência "Literatura infantil, formação de cânones e avaliação literária" (Metzler, 2003) é a contrapartida teórica desse léxico, refletindo sobre os processos de canonização subjacentes aos quais os clássicos das crianças estão sujeitos.

Desde que estudei História da Arte, estou particularmente interessada nas relações texto-imagem na literatura infantil. Consequentemente, lidei extensivamente com o livro ilustrado e também colecionei livros ilustrados.

Um primeiro resultado dessa atividade coletora e discussão científica 
surgiu em colaboração com meu marido Jörg Meibauer, professor de Linguística da Universidade de Mainz [Mogúncia]. Adotamos os chamados livros de figuras para bebês, assim como livros ilustrados para crianças a partir dos doze meses, que retratam apenas objetos individuais do ambiente da criança, como uma bola, uma banana, um par de sapatos ou uma colher. Esses livros ilustrados são negligenciados na pesquisa de livros ilustrados até hoje. No entanto, tentamos mostrar que esse tipo de livro ilustrado promove a aquisição da linguagem, a aquisição do letramento visual e literário da criança pequena e introduz a criança no meio dos livros de figuras. Desde então, preocupamo-nos principalmente com os aspectos cognitivos do livro ilustrado.

Em 2007, foi realizada uma conferência internacional de livros ilustrados em Barcelona, organizada por mim e duas colegas de lá. A partir disso, desenvolveu-se uma rede europeia informal de pesquisadores de livros ilustrados. Desde então, as conferências sobre ilustrações acontecem a cada dois anos na Europa, até agora em Glasgow, Tübingen [Tubinga], Estocolmo, Danzig e Pádua, este ano em Bergen (Noruega). Como estou ativamente envolvida nessa rede, tenho publicado cada vez mais nessa área, às vezes em colaboração com meu marido. O resultado final dessa especialização é o "Routledge Companion to Picturebooks" publicado por mim (Nova York, 2018), o primeiro manual de pesquisa de livros ilustrados.

3. Atualmente, grupos conservadores no Brasil estão tentando censurar ou proibir livros infantis (e, ainda, exposições de arte) porque acreditam que alguns incluem problemáticas de cunho sexual ou moral inadequado para as crianças. Por outro lado, há notícias sobre uma escola em Barcelona, onde mesmo as pessoas que se identificam com o progressismo intencionavam banir os contos de fadas nas escolas, porque acreditam que eles contenham elementos de sexismo. Como a Sra. vê essa situação e ocorre algo semelhante na Alemanha de hoje? Existe anacronismo nesse sentido? 
As controvérsias correspondentes ao impacto e a seleção da literatura infantil têm sido recorrentes e são provocadas por debates apropriados, como o MéToo ou a demanda pelo politicamente correto. Da mesma forma, razões ideológicas e políticas desempenham um papel importante quando se trata da censura da arte e da literatura infantis. Os contos de fadas também foram repetidamente atacados porque seriam brutais, transmitiriam estereótipos de gênero desatualizados, etc. Por um lado, é preciso levar em conta o fato de que muitos contos de fadas (folclóricos) nem sequer foram escritos para crianças. Por outro lado, os contos de fadas, como os dos Grimm, pertencem à herança cultural. Simplesmente proibi-los de serem indexados ou renovados não é uma solução porque isso consiste em paternalismo. Certos contos de fadas certamente não são adequados para crianças muito pequenas - mas esse não é realmente o público-alvo - , e sim para crianças mais velhas, se não adultos. Eu acho que foi o Bettelheim quem exigiu o direito da criança aos contos de fadas. $\mathrm{Na}$ Alemanha, o conto de fadas faz parte da leitura escolar na $4^{\mathrm{a}}$ série [equivalente ao ensino fundamental] e novamente na $6^{\mathrm{a}}$ série, como uma introdução à teoria dos gêneros (chamadas formas pequenas), mas também como uma introdução a estruturas narrativas prototípicas e constelações de figuras.

Atualmente, não há controvérsia sobre contos de fadas na Alemanha. Há alguns anos, no entanto, houve uma discussão nacional sobre "palavrões" como "negro" na literatura infantil, desencadeada por uma entrevista da então ministra da Família Kristina Schröder na ZEIT (uma revista semanal). Como resultado, alguns livros infantis foram "censurados" substituindo a palavra "negro" por outra. Isso não resolve o problema, porque aqui apenas uma palavra é trocada por outra. O tópico subjacente - existe um racismo estrutural? - não é afetado. Na ocasião deste debate, foi realizada uma conferência no PH Karlsruhe em 2014, na qual pesquisadores de diferentes disciplinas assumiram posições diferentes nesta discussão, que apareceu em uma antologia em 2015. 


\section{Qual o papel dos contos de fadas no pós-modernismo? São escritos para crianças?}

O conto de fadas continua a desempenhar um papel de destaque na literatura infantil moderna, apesar ou talvez por causa do pós-modernismo. Além das novas edições de contos de fadas famosos (Grimm, Perrault, Andersen, etc.), principalmente na forma de edições ilustradas ou livros ilustrados de contos de fadas, existem contos de fadas modernos para crianças, que geralmente se referem intertextualmente a contos e paródias conhecidos, e recontam as narrativas, adicionam novos personagens ou histórias, etc. Portanto, existem inúmeras novas versões dos contos de fada de Chapeuzinho Vermelho, Branca de Neve ou foão e Maria, que diferem da versão original por uma nova conclusão, o papel dos personagens é alterado ou a ação é movida para um cenário atual. Essas tendências podem ser encontradas tanto no livro ilustrado quanto no romance para crianças e adolescentes. Nos romances juvenis, os contos de fadas correspondentes são reinterpretados, abordando tópicos como escolha errada do parceiro, abuso sexual, ideologia política, até o Holocausto, com referência a contos de fadas conhecidos e apresentando-os sob uma luz distinta. Um foco especial é frequentemente a perspectiva de gênero, questionando as relações de poder tradicionais (o príncipe sempre precisa resgatar a princesa, não pode ser o contrário?). Também deve ser lembrado que os contos de fadas para crianças também estão muito presentes em outras mídias, como o filme, a história em quadrinhos ou o jogo de computador. Portanto, acho que o conto de fadas continuará a desempenhar um papel importante na literatura infantil e na mídia infantil no futuro.

5. Quanto às ilustrações do livro ilustrado de contos de fadas: elas limitam a imaginação dos leitores ou as enriquecem?

Você mesmo pode discutir sobre isso com excelência. Deve-se enfatizar, 
no entanto, que mesmo as primeiras coleções de contos de fadas (Grimm, Perrault, Andersen) já estavam ilustradas. Mesmo que não sejam livros ilustrados, a ilustração sempre desempenhou um papel essencial nos contos de fadas. Isso já pode ser demonstrado pelas inúmeras edições ilustradas de contos de fadas famosos e artísticos. Hoje, o livro ilustrado de contos de fadas domina. Aqui deve-se proceder a uma distinção sobre se é uma ilustração subsequente de um conto de fadas já existente, como nos contos de fadas de H.C. Andersen e E.T.A. Hoffmann, ou são sobre contos de fadas recém-escritos ou adaptações de contos de fadas, criados em estreita associação com as ilustrações. Se esses livros ilustrados dificultam ou enriquecem a imaginação, depende da qualidade e validade das imagens. Existem muitos livros ilustrados com ilustrações mal pintadas que pouco contribuem para estimular a imaginação. Por outro lado, no entanto, existem livros ilustrados de contos de fadas de design excelentes que adicionam uma nova faceta aos conhecidos contos de fadas. Menciono aqui apenas os livros ilustrados de Anthony Browne, Susanne Janssen, Felix Hoffmann e Henriette Sauvant. Esses ilustradores são capazes de dar vida aos personagens e dar-lhes traços individuais - algo que não está ou está subliminarmente presente nos textos subjacentes aos contos de fadas. Ao mesmo tempo, eles reinterpretam os contos de fadas dessa maneira e chamam a atenção para aspectos que você talvez nunca tenha considerado ou visto antes.

\section{Pode-se identificar uma (nova) tendência em novos contos de fadas de criação recente? Qual seria?}

O que observei no conto de fadas atual no campo da literatura infantil, já respondi na pergunta 4 em termos de pós-modernismo. Não acho que novos contos de fadas para crianças sejam escritos na Alemanha hoje. A tendência aponta na direção da re-ilustração de contos de fadas conhecidos ou da reescritura de contos de fadas para parodiar e satirizar. 
7. A pesquisa brasileira sobre contos de fadas e livros ilustrados não está muito ligada à pesquisa internacional sobre esses temas, devido às dificuldades de alguns pesquisadores e leitores com o domínio de línguas estrangeiras. $\mathrm{O}$ que a Sra. pensa sobre como poderíamos superar esse problema? Com mais tradução de textos importantes? Com mais congressos internacionais no Brasil?

Eu acho que tem-se de seguir caminhos diferentes aqui. Um aspecto importante é primeiro a rede no Brasil, por exemplo, fundando uma rede ou sociedade para a literatura infantil, com oficinas regulares e pequenas conferências. A partir daí, é mais fácil encontrar uma conexão com a pesquisa internacional. O pré-requisito é, é claro, a capacidade de ler literatura inglesa e até de dar palestras em inglês. Como o inglês se tornou o idioma científico internacional, não há como contorná-lo. Eu acho que a geração mais jovem de pesquisadores certamente tem menos problemas com isso. Obviamente, pode-se pensar em traduzir literatura importante para o português. Então você pode alcançar um número maior de leitores e professores. No entanto, para estabelecer um contato ativo e trocar ideias com pesquisadores internacionais, existe realmente apenas a opção de participar de conferências internacionais e organizar conferências internacionais no Brasil. Essas conferências não precisam ser grandes, 15 a 25 palestras são suficientes e contribuem para um intercâmbio melhor e mais intensivo. Outra opção é a publicação de ensaios em inglês em periódicos internacionais, que estão sujeitos a um processo de avaliação. Essa é uma maneira muito boa de promover a visibilidade da pesquisa em literatura infantil brasileira (incluindo pesquisas de contos de fadas e livros ilustrados).

8. No mundo acadêmico do Brasil, ainda existem preconceitos contra a pesquisa em literatura infantil. Ela é muitas vezes considerada menor e menos importante, ou apenas de cunho pedagógico, o que não é 
sempre verdade. Existe esse preconceito na Alemanha e como podemos superá-lo?

Infelizmente, esses preconceitos também existem em outros países, incluindo a Alemanha. A literatura infantil é geralmente atribuída à pedagogia e, portanto, desempenha um papel primordial nas universidades na formação de educadores e professores. $\mathrm{O}$ fato de a literatura infantil, assim como a literatura para adultos, poder ser estudada sob aspectos históricos, culturais, estéticos e narratológicos, é difícil de transmitir a muitos colegas que não estão familiarizados com a literatura infantil. Afinal, agora existem estudos sobre o fenômeno da literatura cruzada, de modo que obras literárias destinadas a crianças e adultos (um excelente exemplo são os romances de Harry Potter) e a influência da vanguarda na literatura infantil e a influência da literatura infantil na literatura, e correntes de vanguarda na primeira metade do século XX. Estudos adicionais devem ser seguidos, indicando as semelhanças e interfaces da literatura infantil e da literatura adulta. Você pode superar esses preconceitos apenas com publicações apropriadas e projetos maiores, ou seja, redes de pesquisa (nacionais e internacionais), também para atrair recursos de instituições como a UE [União Europeia] e instituições similares.

\section{Os contos de fadas são sempre literatura infantil? $O$ que pensa a respeito?}

Em geral, eu não concordaria, porque os contos populares tradicionais nunca foram destinados a crianças, mesmo que as crianças estivessem entre os ouvintes. Mas existem contos de fadas escritos para crianças, como os contos de fadas infantis "The Strange Child" e "Nutcracker and Mouse King" de E.T.A. Hoffmann ou os contos de fadas de Hans Christian Andersen. Os contos de fadas de Grimm não eram originalmente destinados a crianças, 
mas foram revisados a partir da $2^{\mathrm{a}}$ edição para um público de leitura infantil. Os chamados contos de fadas artísticos se comportam da mesma forma: existem muitos para os leitores adultos, mas também contos de fadas para crianças. Na Alemanha, aqui estão os contos de Theodor Storm ("The little Häwelmann", "The Regentrude”), os contos proletários para crianças nas décadas de 1920 e 1930 (de Edwin Hoernle, Hermynia zur Mühlen, Bruno Schönlank, etc.). Portanto, você deve examinar com cuidado quem eram os leitores pretendidos. Independentemente disso, os contos de fadas na literatura infantil também desempenham um papel na medida em que são fornecidas referências intertextuais aos contos de fadas e o livro ilustrado de contos de fadas está desfrutando de crescente popularidade.

Io. Apesar do preconceito de alguns acadêmicos, há um enorme interesse em contos de fadas e eventos sobre esse tema no Brasil. É o mesmo na Alemanha? Há interesse dos seus alunos neste tópico?

O interesse em contos de fadas também é generalizado na Alemanha, tanto no meio acadêmico quanto na população em geral. Os eventos são oferecidos por centros de educação de adultos, pela Sociedade Europeia de Contos de Fadas, academias, etc. O conto de fadas é recebido com grande interesse entre os estudantes. De vez em quando, ofereço um seminário, mais recentemente no semestre de inverno, com o título "Conto de fadas de Grimms intermediário”. Os alunos conhecem os contos de fadas através de filmes de contos de fadas, séries de televisão como "SimsalaGrimm", leitura de contos de fadas, jogos de computador, etc.

I I. Na sua opinião, quais são os centros de pesquisa mais importantes para contos de fadas e livros ilustrados do mundo hoje? (Não apenas universidades.) 
$\mathrm{Na}$ Alemanha, eu citaria aqui especialmente a Universidade de Göttingen. Não há centros de pesquisa para o livro ilustrado em todo o mundo, mesmo que universidades individuais estejam preocupadas com a exploração do livro ilustrado. Mas essa área é simplesmente nova demais e teoricamente precisa se desenvolver ainda mais. Por outro lado, existem centros ou institutos de literatura infantil. $\mathrm{Na}$ Alemanha, por exemplo, este seria o Instituto para o Estudo de Livros Jovens da Universidade de Frankfurt, na Suécia, o Stockholm Barnboksinstitutet (Instituto do Livro Infantil), que trabalha em estreita colaboração com a Universidade de Estocolmo, ou na França, o Instituto Charles Perrault em Eaubonne, perto de Paris. A Inglaterra tem várias prioridades de pesquisa no campo da literatura infantil, nas universidades de Glasgow, Roehampton, Newcastle e Cambridge. Estes são apenas alguns centros ou institutos, uma enumeração iria longe demais aqui.

No que diz respeito ao estudo científico de livros ilustrados, só posso apontar para a "Rede Europeia de Pesquisa de Livros Ilustrados", que oferece uma conferência internacional a cada dois anos em um país europeu. Essa rede é extremamente bem-sucedida e reúne colegas de todo o mundo que estão explorando o livro ilustrado. Seria desejável se resultasse em um centro ou agrupamento de núcleos de pesquisa.

Muito obrigada! 


\section{Prof. Dr. Bettina Kümmerling-Meibauer: currículo resumido}

Bettina Kümmerling-Meibauer é professora no "Deutsches Seminar" [Departamento de Germanística] der Eberhard-Karls-Universität Tübingen, Alemanha. Atuou como professora visitante convidada na Universidade Linné-Växjö / Kalmar na Sucécia e na Universidade de Viena, Áustria. Ela é especialista em internacionalização de livros na Universidade de Inverno (Heidelberg) e na Editora John Benjamins (Amsterdã) e no Conselho Editorial de publicações internacionais: Literatura Internacional: Literatura Infantil (IRCL) e Libri \& Liberi. Projetos de pesquisa internacionais: Literatura Infantil e Juvenil Internacional, Pesquisa em Literatura, Pesquisa em Alfabetização, Pesquisa em Cinema Infantil, Literatura Infantil e Avantgarde, Literatura Infantil na RDA [República Democrática Alemã].

\section{Participações em associações e redes internacionais}

2017-2020: Membro do Comitê Internacional da Associação de Literatura Infantil da América

2015-2019: Membro do Comitê de Gestão do projeto COST “Literacia Digital e Práticas Multimodais da Criança”, financiado pela UE.

2012-2021: Membro do projeto de pesquisa internacional "Our Mythical Childhood. Clássicos em Literatura Infantil entre Leste e Oeste”, patrocinado pela Loeb Classic Library Foundation, Harvard, MA; Fundação Humboldt e um subsídio inicial do ERC.

2012-2015: Membro da equipe de especialistas do "Lesestart", financiado pelo BMBF e realizado pelo Stiftung Lesen

2011-2012: Presidente do projeto de pesquisa internacional "Literatura infantil e 
vanguarda européia”, financiado pela European Science Foundation

2010-2016: Membro do grupo de pesquisa da rede de pesquisa "Placim: rumo a uma plataforma para a investigação da história e teoria das mídias infantis”

2007: Co-fundador da rede "Rede Europeia de Pesquisa de Livros de Figuras"

2004-2006: Membro do grupo internacional de pesquisa "NORCHILNET", financiado pelo Reichsbank sueco e pelo Ministério sueco de Ciência e Pesquisa

2001/02: Presidente do júri do prêmio especial "Prêmio pelas obras completas de um tradutor" no âmbito do Prêmio Alemão para a Literatura Juvenil

Organização de dez conferências internacionais, patrocinadas por: Fundação Fritz Thyssen (3), DFG, Fundação Europeia da Ciência, Fundação Japão, Centro de Pesquisa Interdisciplinar (Bielefeld), Centro de Pesquisa Astrid Lindgren, KidsRegio

Participação em sociedades científicas: Sociedade Internacional de Pesquisa em Literatura Infantil; Associação de Literatura Infantil da América; Sociedade Alemã de Pesquisa em Literatura Infantil; Sociedade Austríaca de Literatura Infantil; Grupo de trabalho para literatura infantil.

\section{Publicações selecionadas (apenas monografias e coletâneas)}

Kümmerling-Meibauer (Org.). 2018. The Routledge Companion to Picturebooks. New York: Routledge. 
Kümmerling-Meibauer \& Anja Müller (Org.). 2017. Canon Change and Canon Constitution in Children's Literature. New York: Routledge.

Nina Goga \& Kümmerling-Meibauer (Org.). 2017. Maps and Mapping in Children's Literature. Amsterdam: John Benjamins.

Elina Druker \& Kümmerling-Meibauer (Org.). 2015. Children's Literature and the Avant-Garde. Amsterdam: John Benjamins. Edited Book Award 2017 der Children's Literature Association; Edited Book Award 2017 der International Research Society for Children's Literature (IRSCL)

Kümmerling-Meibauer, Jörg Meibauer, Kerstin Nachtigäller \& Katharina Rohlfing (Org.). 2015. Learning from Picturebooks. New Trends in Literacy Studies and Child Development. New York: Routledge.

Kümmerling-Meibauer (Org.). 2014. Picturebooks. Representation and Narration. New York: Routledge.

Kümmerling-Meibauer \& Ira Gawlitzek (Org.). 2014. Kinderliteratur und Mehrsprachigkeit. Stuttgart: Filibach-Klett.

Susanne Blumesberger, Kümmerling-Meibauer, Jana Mikota \& Ernst Seibert (Hgg.). 2014. „Hieroglyphe der Epoche“? Zum Werk der österreichisch-jüdischen Autorin Anna Maria Jokl. Wien: Praesens.

Jaqueline Berndt \& Kümmerling-Meibauer (Org.). 2013. Manga’s Cultural Crossroads. New York: Routledge.

Kümmerling-Meibauer. 2012. Kinder- und Jugendliteratur. Eine Einführung. Darmstadt: Wissenschaftliche Buchgesellschaft. 
Christian Exner \& Kümmerling-Meibauer (Org.). 2011. Von Wilden Kerlen und Wilden Hühnern. Perspektiven des modernen Kinderfilms. Marburg: Schüren.

Kümmerling-Meibauer \& Astrid Surmatz (Org.). 2011. Beyond Pippi Longstocking. International and Intermedial Aspects of Astrid Lindgren's Work. New York: Routledge.

Kümmerling-Meibauer (Org.). 2011. Emergent Literacy. Children's books from 0 to 3. Amsterdam: John Benjamins.

Teresa Colomer, Kümmerling-Meibauer \& Cecilia Silva-Díaz (Org.). 2010. New Directions in Picturebook Research. New York: Routledge.

Kümmerling-Meibauer \& Thomas Koebner (Org.). 2010. Filmgenres: Kinder- und Jugendfilm. Stuttgart: Reclam.

Svenja Blume, Kümmerling-Meibauer \& Angelika Nix (Org.). 2009. Astrid Lindgren. Werk und Wirkung. Frankfurt: Peter Lang.

Kümmerling-Meibauer. 2003. Kinderliteratur, Kanonbildung und literarische Wertung. Stuttgart \& Weimar: Metzler.

Kümmerling-Meibauer. 1999. Klassiker der Kinder- und Jugendliteratur. 2 Bde. Stuttgart \& Weimar: Metzler (Neuausgabe 2006).

Kümmerling-Meibauer. 1991. Die Kunstmärchen von Hofmannsthal, Musil und Döblin. Weimar: Böhlau. 